\title{
Utilization of Nanomaterials in Conductive Smart- Textiles: A Review
}

\author{
Bapan Adak ${ }^{1,2 *}$ \\ ${ }^{1}$ Product Development Department, Kusumgar Corporates Pvt. Ltd, India \\ ${ }^{2}$ Department of Textile Technology, Indian Institute of Technology Delhi, India
}

*Corresponding author: Bapan Adak, Product Development Manager, Kusumgar Corporates Pvt Ltd, India.

Received Date: February 24, 2021

Published Date: April 08, 2021

\begin{abstract}
Recently, conductive textiles are being utilized extensively in a wide range of smart applications such as sensors, textile batteries, supercapacitors, electrostatic discharge clothing, heating textiles and many more. This review highlights the role of various conductive nanomaterials in developing conductive textiles. Different conductive nanomaterials, their advantages and disadvantages, their potential for improving conductivity of textiles and various applications of conductive textiles have been summarized in this review.
\end{abstract}

Keywords: Conductive textiles; CNT; Graphene; MXene; Nanocoating; Polymer nanocomposite

\section{Introduction}

Metallic filaments (such as steel, copper, aluminum etc.) and intrinsically conducting polymers (ICPs) such as polypyrrole (PPy), polyaniline (PANI), polyacetylene, polythiophene, poly(3,4ethylenedioxythiophene)- poly(styrene sulfonate) (PEDOT:PSS) etc. are being used from a long run in conventional conductive textiles [1-3]. However, these conventional conductive textiles have many limitations. Recently, nanotechnology has offered growing interest for developing conductive smart textiles through the incorporation of active conductive nanomaterials in textiles [4-5]. Especially, increased attention has been given to different carbonbased nanomaterials (carbon nanotubes (CNTs) and graphene), metallic nanomaterials and MXene because of their high electrical and thermal conductivity. The recent developments in this field have been summarized in this review.

\section{Conductive Nanofillers}

\section{Conductive metallic nanomaterials}

Conductive metals (such as silver, copper, gold, aluminum, and tin) and metal oxide $\left(\mathrm{TiO}_{2}\right.$ and $\left.\mathrm{ZnO}\right)$ nanomaterials exhibit great promise as alternatives to conventional conductive materials [6-8]. These conductive metal nanomaterials (nanoparticles or nanowires) can be incorporated in different polymers to make conductive polymer nanocomposites, which can be used further for making conductive fibers or coated textiles. However, in polymer matrices, generally, metal nanowires exhibit better conductivity in comparison to metal nanoparticles because of their better conductive network at lower concentrations and less inter-particle junctions in the case of nanowires [9]. Conductive nanoparticles such $\mathrm{Ag}, \mathrm{ZnO}$ and $\mathrm{TiO}_{2}$ dissipate the static charge of synthetic fibers because of their good electro-conductive property and hence, these nanoparticles can be used to develop antistatic fabrics [10-11].

\section{Carbon-based nanomaterials}

Different carbon-based nanomaterials such as 2D graphite and graphene, 1D CNTs, carbon black etc. are extensively used to increase conductivity of polymer and textiles [12-14]. The electrical conductivity, of pure CNT can be as high as $10^{6}$ to $10^{7} \mathrm{~S} \mathrm{~m}^{-1}$ and for pure graphene, it can be up to $10^{5} \mathrm{~S} \mathrm{~m}^{-1}$. On the other hand, the thermal conductivity value of CNT may vary between $2800-6000$ 
$\mathrm{W} \mathrm{m} \mathrm{m}^{-1} \mathrm{~K}^{-1}$ (in longitudinal direction), where for graphene it may be as high as $5000 \mathrm{~W} \mathrm{~m}^{-1} \mathrm{~K}^{-1}$ [14]. Because of such high thermal and electrical conductivity, CNT and graphene have great potential for enhancing the conductive property of textiles. In an interesting study, Chen, et al. [15] studied the effect of different carbon-based nanomaterials and their aspect ratios on the thermal conductivity of epoxy nanocomposites, where the thermal conductivity increased with increasing filler concentration and aspect ratio. Moreover, graphene oxide (GO) showed the best thermal conductivity, while carbon black showed the most inferior performance [15].

\section{MXene}

MXene is a metal carbide or nitride-based emerging 2D nanomaterial with very high electrical conductivity up to $9880 \mathrm{~S} \mathrm{~cm}^{-1}$ [16-17]. It is represented with a general formula of $M_{n+1} X_{n} T_{x}$ (where $\mathrm{M}$ is a transition metal, $\mathrm{X}$ is carbon and/or nitrogen, Tx represents the functional groups such as $\mathrm{O}, \mathrm{OH}, \mathrm{Cl}$ and $\mathrm{F}$ ). MXene, especially $\mathrm{Ti}_{3} \mathrm{C}_{2} \mathrm{~T}_{\mathrm{x}}$ nanosheets have already been proven as an excellent electrode material because of its very high conductivity, large surface area, surface functionalities, rich physical and chemical properties, high specific capacitance and power density [17-18].

Recently Yan, et al. [16] prepared PPy-MXene coated textile by two-step method - (i) dipping of textile in MXene solution and drying, (ii) electrochemical deposition of PPy on MXene-textiles, resulting in very high specific capacitance of $343.20 \mathrm{~F} \mathrm{~g}^{-1}$, energy density of $1.30 \mathrm{~mW} \mathrm{~h} \mathrm{~g}^{-1}$ (power density $=41.1 \mathrm{~mW} \mathrm{~g}^{-1}$ ), which is much higher than the values reported in other studies for carbon nanotubes (CNTs) and active carbon, showing a good potential for supercapacitors, flexible and wearable energy storage devices [16]

\section{Techniques for making conductive textile by incorporating nanomaterials}

There are many techniques for making nano-enhanced conductive smart textiles. The different techniques for incorporation of conductive nanofillers in textiles are -

1. Finishing of textiles using conductive nanofillers by dip and dry method or layer-by-layer (LbL) deposition [19]

2. Nanocoating of conductive fillers on textiles by different techniques such as sputter coating, chemical vapor deposition (CVD), electroless plating etc. [20]

3. Coating of conductive polymer nanocomposites on textiles [16]

4. Use of conducting polymer nanocomposite fibers for making conductive yarn/fabric [18]

5. Preparation of polymer nanocomposite-based nanofibers by electrospinning process [21]

\section{Applications of conductive textiles}

In conjugation with conductive nanomaterials, textiles offer many smart features for high-performance applications such as electroconductive textiles, EMI shield textiles, antistatic textiles, textile-sensors, textile batteries, supercapacitors, piezo-electric textiles, thermoregulating textiles, wearable antenna photonic textiles and many others [4,9,22], as summarized in Figure 1. Recently, conductive smart textiles have huge demand coving a wide range of application areas such as healthcare, sports, workwear and many other technical fields.

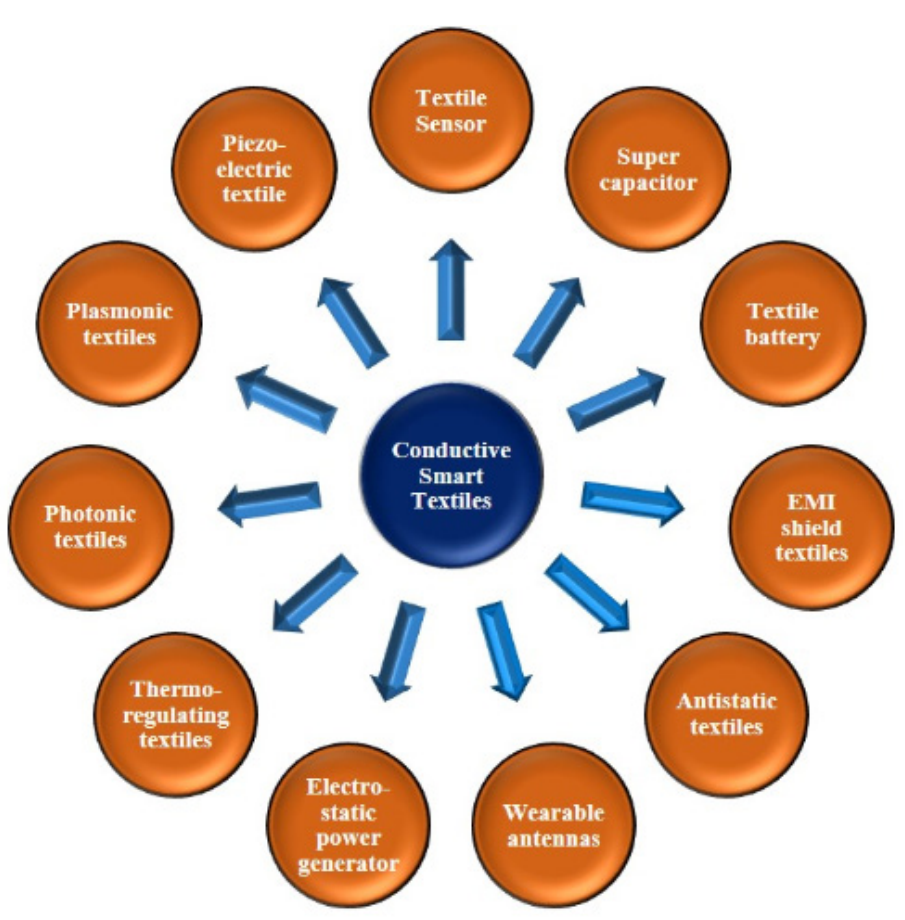

Figure 1: Potential applications of nano-enhanced conductive smart-textiles. 


\section{Conclusion}

In summary, different conductive nanofillers have huge potential for enhancing the conductive property of materials which will drive the futuristic development of smarter conductive textiles for multi-direction applications.

\section{Acknowledgment}

None.

\section{Conflict of Interest}

Author declares no conflict of interest.

\section{References}

1. Kaur G, Adhikari R, Cass P, Bown M, Gunatillake P (2015) Electrically conductive polymers and composites for biomedical applications. Rsc Advances 5(47): 37553-37567.

2. Maity S, Chatterjee A (2015) Textile/polypyrrole composites for sensory applications. Journal of Composites.

3. Ouyang J (2018) Recent advances of intrinsically conductive polymers. Acta Physicochimica Sinica 34(11): 1211-1220.

4. Joshi M, Adak B (2019) Advances in nanotechnology based functional, smart and intelligent textiles: a review. In: Andrews DL, Lipson RH, Nann $\mathrm{T}$ (edts), Comprehensive Nanoscience and Nanotechnology, $\left(2^{\text {nd }} \mathrm{edn}\right)$, Elsevier, pp. 253-290

5. Coyle S, Wu Y, Lau KT, De Rossi D, Wallace G, et al. (2007) Smart nanotextiles: a review of materials and applications. MRS bulletin 32(5): 434-442.

6. Naghdi S, Rhee KY, Hui D, Park SJ (2018) A review of conductive metal nanomaterials as conductive, transparent, and flexible coatings, thin films, and conductive fillers: Different deposition methods and applications. Coatings 8(8): 278.

7. Xue CH, Chen J, Yin W, Jia ST, Ma JZ (2012) Superhydrophobic conductive textiles with antibacterial property by coating fibers with silver nanoparticles. Applied Surface Science 258(7): 2468-2472.

8. Karimi L, Yazdanshenas ME, Khajavi R, Rashidi A, Mirjalili M (2014) Using graphene $/ \mathrm{TiO}_{2}$ nanocomposite as a new route for preparation of electroconductive, self-cleaning, antibacterial and antifungal cotton fabric without toxicity. Cellulose 21(5): 3813-3827.

9. Atwa Y, Maheshwari N, Goldthorpe IA (2015) Silver nanowire coated threads for electrically conductive textiles. Journal of Materials Chemistry C 3(16): 3908-3912.

10. Zhang F, Yang J (2009) Preparation of nano-ZnO and its application to the textile on antistatic finishing. International Journal of Chemistry 1(1): 18.
11. Joshi M, Adak B (2018) Nanotechnology-based Textiles: A Solution for Emerging Automotive Sector. Rubber Nanocomposites and Nanotextiles; De Gruyter: Berlin, Germany: 207-266.

12. Karim N, Afroj S, Malandraki A, Butterworth S, Beach C, et al. (2017) All inkjet-printed graphene-based conductive patterns for wearable e-textile applications. Journal of materials chemistry C 5(44): 1164011648.

13. Trovato V, Teblum E, Kostikov Y, Pedrana A, Re V, et al. (2020) Solgel approach to incorporate millimeter-long carbon nanotubes into fabrics for the development of electrical-conductive textiles. Materials Chemistry and Physics 240: 122218.

14. Martin-Gallego M, Verdejo R, Khayet M, de Zarate JMO, Essalhi M, et al. (2011) Thermal conductivity of carbon nanotubes and graphene in epoxy nanofluids and nanocomposites. Nanoscale research letters 6(1): $1-7$.

15. Chen J, Gao X, Song W (2019) Effect of various carbon nanofillers and different filler aspect ratios on the thermal conductivity of epoxy matrix nanocomposites. Results in Physics 15: 102771.

16. Yan J, Ma Y, Zhang C, Li X, Liu W, et al. (2018) Polypyrrole-MXene coated textile-based flexible energy storage device. RSC advances 8(69): 39742 39748.

17. Ahmed A, Hossain MM, Adak B, Mukhopadhyay S (2020) Recent Advances in 2D MXene Integrated Smart-Textile Interfaces for Multifunctional Applications. Chemistry of Materials 32(24): 10296-10320.

18. Seyedin S, Uzun S, Levitt A, Anasori B, Dion G, et al. (2020) MXene composite and coaxial fibers with high stretchability and conductivity for wearable strain sensing textiles. Advanced Functional Materials 30(12): 1910504

19. Ahmed A, Jalil MA, Hossain MM, Moniruzzaman M, Adak B, Islam, et al. (2020) A PEDOT: PSS and graphene-clad smart textile-based wearable electronic Joule heater with high thermal stability. Journal of Materials Chemistry C 8(45): 16204-16215.

20. Chatterjee K, Tabor J, Ghosh TK (2019) Electrically conductive coatings for fiber-based e-textiles. Fibers 7(6): 51.

21. Abdali H, Ajji A (2017) Preparation of electrospun nanocomposite nanofibers of polyaniline/poly (methyl methacrylate) with aminofunctionalized graphene. Polymers 9(9): 453

22. Fu KK, Padbury R, Toprakci O, Dirican M, Zhang X (2018) Conductive textiles. In: Miao, M., Xin, J. H. (edts), Engineering of High-Performance Textiles, Woodhead Publishing, UK, pp. 305-334. 